\title{
A New Example for the Use of Information Technologies in Education: Geographic Information Systems
}

\author{
Nihal BALOĞLU UĞURLU*
}

\begin{abstract}
Current innovative ideas and changes in education bring the integration of education system with information technologies in the foreground in owing to technological improvements. Therefore, it is aimed to educate students as active participants with high self-confidence and contemporary ideas. There are various applications of the information technologies in the K-12 education field. Doubtlessly new ones are added to these applications everyday. The aim of this study is to examine how Geographic Information Systems contribute to the education field and limitations of the use of Geographic Information Systems in education. At the end of the study, suggestions to overcome these limitations and how to diffuse this technology in the education field are presented.
\end{abstract}

Key Words: Information Technology, Geographic Information Systems, Contemporary Education.

\section{SUMMARY}

In $21^{\text {st }}$ century where information is generatively developed rapidly, teaching approaches based upon accessing to information, using it and production skills have become important. In order to that these teaching approaches can support students' different-sized developments teaching

* Ass. Prof. Dr., Nigde University, Faculty of Education, Department of Primary School Teaching, e-mail: nihalugurlu@nigde.edu.tr. 
environments where different information technologies are used are necessary. Geographic Information Systems (GIS), one of the information technologies, is an information technology that can be used in teaching field in this sense.

In addition to its functional features that can be used by different disciplines, the most important reason for GIS to be used in teaching field is that information can be presented by different representations (map, graphic, picture, digital information) for teaching purpose. Interactively one-to-one presentation of these representations to students makes students being more active and motivated by using this technology in teaching environment.

There are many studies emphasizing the contributions of GIS to teaching environment. Common attributes drawing most attention to the use of GIS in teaching environment in these studies are that GIS is a studentcentered application and eases active learning, that it improves spatial knowledge and skills of students (Lee, 2005, Xioamin 2006, Broda \& Baxter, 2002; Keiper, 1999), that it improves social learning skills of students by encouraging them to collaboration (Hagevik, 2003, Baker, 2001), that it facilitates learning of students by providing integrity between different disciplines (Johansson \& Pellikka, 2005, Broda \& Baxter, 2002, Drennon, 2005) and that it improves students' skills on using information technologies (Tschirner \& O’Brien, 2006, Wechsler \& Pits, 2004).

In spite of its useful characteristics in teaching environment, there are a few reasons that limit the use of GIS in educational institutions. These limitations are faced most in teachers' situation. Inadequate technical and pedagogical knowledge of teachers about GIS software (Johannson, 2003, Moore, Brady, Bursek \& Francis, 2004, Baker, 2005, Bartha 2005) and having limited time for preparing GIS exercises and for integrating this technology with lesson plan and classroom activities (Butterick, Olkin \& Zack, 1999, Bednarz 1999, Alibrandi \& Palmer, 2001, Kerski, 2003, Meyer, Hagevik, 2003, Johansson \& Pellikka, 2005) are two of the highlighted problems in terms of teachers.

Besides, several problems can arise to establish technical infrastructure for performing GIS applications in educational institutions. The most important ones are high-costs of software (Wiegand, 2001, Johansson, 2003, Kerski, 2003), having difficulties in getting appropriate basic maps and databases (Wiegand, 2001, Johansson \& Kaivola, 2004, Akt. Bednarz \& Shee, 2006) and inadequate hardware for GIS usage in schools (Kerski, 2003, Walker, 2004). 
There have been some implementations for providing GIS usage in education field in our country in recent years (Demirci, 2006, Aladağ, 2007, Baloğlu Uğurlu, 2007, Koçak, 2007). In addition to these implementations, offering of GIS as an activity in some acquisitions of Geography course teaching program (MEB, 2005) is the first example which makes it necessary to integrate this technology with teaching program. Joining education system of the Ministry of National Education with advanced technologies, supporting it with renovations, improving it continuously with assessments, implementations of the Ministry of National Education to utilize actively from this technology by supplying information technologies means to elementary and secondary education institutions by its information technology vision aimed at providing student-centered and project-based education system by using information technologies at the highest level and construction of approximately 29.264 information technology classes in schools and institutions appertaining to the Ministry with the contributions of foreign, national resources and several private organizations in the frame of these implementations (MEB, 2007) show that these technical infrastructure problems related to the use of GIS in educational institutions can be surmounted. Following of these implementations, approval of the project of "use of GIS technology for making project-based and practical education become widespread in geography education" in the meeting of the Ministry of National Education with TUBITAK (TUBITAK-MEB, 2007) is another important progress.

In conclusion, attempts for making GIS become widespread in education institutions are continuing in our country as in around the world. It is possible to have some problems in GIS applications as is the case in every innovative attempt. However, developing technology and basic GIS skills, which is one of the products of modern education system, should be brought in students beginning from elementary level in order to train coming generation up as more active, participator and information producing individuals. 


\title{
Eğitimde Bilgi Teknolojilerinin Kullanımına Yeni Bir Örnek: Coğrafi Bilgi Sistemleri
}

\begin{abstract}
Nihal BALOĞLU UĞURLU*
ÖZ. Günümüzde her alanda olduğu gibi eğitim alanında da yaşanan yenilikçi düşünce ve değişimler, teknolojik gelişmelerin ışığında eğitim sisteminin bilgi teknolojileri ile bütünleştirilmesini ön plana çıkarmaktadır. Bu sayede öğrencilerin öğretim sürecine dahil edilerek çağdaş düşünce yapısına sahip, aktif ve katılımcı, özgüveni yüksek bireyler olarak yetiştirilmeleri planlanmaktadır. Bilgi teknolojilerinin ilk ve ortaöğretim kurumlarında kullanımı ile ilgili çeşitli uygulamalar mevcuttur. Şüphesiz bu uygulamalara her geçen gün bir yenisi daha eklenmektedir. Bu çalışmanın amacı, bir bilgi teknolojisi olan Coğrafi Bilgi Sistemleri'nin eğitim alanına nasıl bir katkıda bulunacağını, bunun yanında eğitim amaçlı Coğrafi Bilgi Sistemleri'nin uygulamalarındaki sinırlılıkların neler olduğunu incelemektir. Çalışmanın sonunda bu bilgi teknolojisinin eğitim açısından sınırlılıklarının aşılması ve yaygınlaştııılması ile ilgili çözüm önerileri sunulmuştur.
\end{abstract}

Anahtar Sözükler: Bilgi Teknolojileri, Coğrafi Bilgi Sistemleri, Çağdaş Ĕ̆itim.

* Yrd. Doç. Dr., Niğde Üniversitesi Eğitim Fakültesi, İlköğretim Bölümü, e-mail: nihalugurlu@nigde.edu.tr. 


\section{GíRIŞ}

Bilginin hızla yenilenerek üretildiği 21. yüzyılda bilgiye ulaşma, bilgiyi kullanma ve üretme becerilerine dayalı ögretim yaklaşımları oldukça önem kazanmaktadır. $\mathrm{Bu}$ becerilerin öğretim süreci ile bütünleştirilmesi ve öğrencilere kazandırılması, bilgi üretimine ve yapılandırılmasına yönelik çağdaş bir eğitimi gerektirmektedir. Nitekim, bilgi ve teknoloji çağı olan günümüzde, son on yıldan beri bazı ülkelerdeki eğitimciler, öğrencilerin farklı boyutlardaki (bilişsel, duyuşsal ve devinimsel) gelişimlerine yönelik olarak bilgi teknolojilerinin kullanımına ihtiyaç olduğunu vurgulamaktadırlar. Buna paralel olarak Türkiye'de de, özellikle son yıllarda, bilgi teknolojileri kullanılarak etkili öğretim modelleri ve materyalleri gerçekleştirmek için yoğun girişimlerde bulunulmaktadır. Bu girişimler, eğitim sistemimizin düşünsel alt yapısını oluşturan tekdüze mantık yerine çoklu sebep ve çoklu sonuçlara dayalı bir anlayışın oluşması yönünde yoğunlaşmaktadır (Çınar, Teyfur \& Teyfur, 2006). Bir bilgi teknolojisi olan Coğrafi Bilgi Sistemleri (CBS)'nin ilk ve ortaöğretim alanında kullanımı bu anlayışın bir yansımasıdır.

\section{Coğrafi Bilgi Sistemleri Nedir?}

CBS coğrafi verilerin depolandığı, düzenlendiği, analiz edildiği ve gösterildiği bir sistemdir. CBS'de veri tabanında yer alan mekânsal ve istatistiksel yapıdaki coğrafi veriler bütünleştirilerek harita, grafik ve sözel gösterimler olarak sunulabilmektedir (West, 2003). Böylece yeryüzüne ait coğrafi özelliklerin sunumu farklı şekillerde gerçekleştirilebilmektedir.

CBS'nin en önemli özelliklerinden biri dinamik olmasıdır. Veriler güncellendiğinde yeni bilgiler coğrafi özelliklere ait görsel sunumların yer aldığ 1 CBS uygulamalarına otomatik olarak yansımaktadır (Wiegand, 2001).

Türkiye'de CBS devletin hemen hemen bütün kurumlarında farklı işlevsel yönleri açısından kullanılmaktadır. Harita Genel Komutanlığı, Tapu ve Kadastro Genel Müdürlüğü, Maden Tetkik ve Arama Genel Müdürlüğü ve belediyeler CBS'nin yaygın olarak kullanıldığı kurumlardan birkaçıdır. $\mathrm{Bu}$ kurumlarda CBS ile mekânsal analizler için temel altlık olarak kullanılacak haritaların sayısallaştırılması işlemleri gerçekleştirilmekte, coğrafi analizler yapılmakta ve yeni bilgiler üretilmektedir. Oysa bilginin eğitim amaçlı olarak farklı gösterimlerle (harita, grafik, resim, sayısal bilgi) sunulabileceği CBS'nin ülkemizdeki ilk ve ortaöğretim kurumlarında kullanımının henüz yaygın olmadığı, bu teknolojinin eğitim alanında uygulanabilirliği ile ilgili çalışmaların çok yeni olduğu görülmektedir. Daha sonra değinileceği gibi bu alanda yapılan çalışmalar öğretim süreci içerisine 
dahil edilen CBS'nin öğrenme ortamlarına olumlu yönde katkıda bulunduğunu göstermektedir.

\section{Coğrafi Bilgi Sistemleri’nin Eğitim Alanına Katkısı}

CBS'nin öğretim süreci içerisinde öğrencilerin farklı zihinsel aktivitelerini ve üst düzey düşünme becerilerini gerçekleştirmeleri için önemli bir teknoloji olduğu araştırmacılar, uygulamacılar ve üreticiler tarafindan sik sik vurgulanmaktadır (ESRI, 1998). CBS'nin bir eğitim teknolojisi olarak kullanımı, farklı boyutlardaki uygulanabilirliği ile ilgilidir.

CBS ögrrenci merkezli ögrrenimi ve aktif öğrenmeyi kolaylaştıran bir uygulamadır. CBS destekli bir öğretim ortamında öğretmen bilgi kaynağı ve bilgiyi aktaran konumdan çıkmakta ve öğrencilerin CBS'yi kullanarak bilgiyi yapılandırmalarında yönlendirici olmaktadır. Böyle bir öğretim ortamı öğrenci merkezli öğrenmeyi destekler. Öğrencilerin öğrenci merkezli bir öğrenme ortamında bilgiyi doğrudan edinen pasif alıcılar değil, bilgiyi kendi istekleri doğrultusunda yapılandırarak zihinlerine işleyen aktif öğrenici durumunda olmaları doğaldır. Bu yolla CBS'nin öğrencilerin kavramsal değişıminde önemli bir rol oynaması, yapısalcı yaklaşımı destekleyen bir özelliğe sahip olduğunu gösterir önemli bir özelliğidir (Duit \& Treagust, 1998).

CBS kullanılarak ögrencilerin mekânsal ögrrenme ile ilgili bilgi ve becerileri gelișir. Öğrencilerin CBS kullanarak geliștirdikleri en önemli becerilerinden biri mekânsal öğrenme ile ilgilidir (Keiper, 1999, Broda \& Baxter, 2002, Lee, 2005, Xioamin 2006).

CBS'nin iki önemli özelliği öğrencilerin mekânsal öğrenme ile ilgili becerilerini geliştirmeye yöneliktir. CBS'nin bu önemli özelliklerinden birincisi farklı harita katmanlarının birleştirilebilmesidir. Harita katmanı üzerinde herhangi bir coğrafi özelliğin mekânsal dağılışını inceleyen öğrenciler farklı harita katmanlarını üst üste bindirdiklerinde o coğrafi özelliğin diğer coğrafi unsurlarla etkileşimini kolaylıkla görebilirler. Örn; herhangi bir tarım ürününün yetiştirildiği alanları bir harita katmanı üzerinde gören öğrenciler bu tarım ürününün yetiştirildiği iklim şartlarını anlamak için bu harita katmanını iklim katmanı ile birleştirebilir ve tarım ürününün yetiştirildiği iklim bölgelerini haritada görebilirler. Böylece öğrencilerin mekânsal ilişkileri zihinlerinde canlandırabilmeleri kolaylaşır. Bu nedenle CBS mekânsal problemlerin anlaşılması, çözüm bulunması ve sonuçların elde edilmesi için etkili bir yoldur.

CBS'nin bilgiyi filtreleme özelliği öğrencilerin mekânsal algılamada kullanabilecekleri bir diğer önemli özelliktir. Öğrenciler CBS’nin bu 
özelliğinden faydalanarak farklı coğrafi sorularına cevap bulabilirler. Öğrenci, "Fırat Nehri havzasında yer alan nüfusu 1000 kişiden fazla olan yerleşim merkezlerini göster" ya da "sanayi alanlarının en yoğun olduğu bölgedeki akarsuları isimlendir" gibi soruların cevaplarını CBS tabanlı haritaları kullanarak kolaylıkla bulabilir.

CBS uygulamaları ögrencileri işbirliğine teşvik ederek sosyal öğrenme becerilerini geliştirir (Baker, 2001, Hagevik, 2003,). Öğrenciler CBS ile araştırmaya dayalı öğretim stratejilerini kullanarak farklı projeler geliştirebilirler. $\mathrm{Bu}$ projeleri geliştirirken ekip çalışması yapmak zorundadırlar. Belirli bir bölgenin CBS uygulamalarının hazırlanması gerektiğinde o bölgenin coğrafi verilerinin toplanması, sınıflandırılması, veri tabanı olarak düzenlenmesi ve farklı şekillerde gösterimi işlemlerinin gerçekleştirilmesi öğrencilerin takım çalışması yapmalarını gerekli kılar. Böylece işbirlikli bir öğrenme gerçekleştirilir. Ayrıca CBS ile öğrencilerin web ortamında bilgi paylaşımı yapmaları da mümkündür. Böylece küreselleşmenin çok sik vurgulandığ 1 günümüzde öğrencilerin yerel projelerini dünya çapında paylaşmaları da söz konusudur.

CBS farklı disiplinler arasında ilişki kurarak bütünlük kazanmalarını sağlar (Broda \& Baxter, 2002, Johansson \& Pellikka, 2005, Drennon, 2005). CBS uygulamaları hazırlanırken o bölgenin coğrafi verilerinin yanı sıra sosyoloji ve ekonomi gibi farklı disiplinlere ait verilerinin elde edilmesi de söz konusudur. CBS ile bu veriler harita katmanları içerisinde bütünleştirilerek kullanıcının o bölgenin özelliklerini farklı disiplinlerin birbiri ile etkileşimi açısından yorumlamalarına yardımcı olur.

CBS öğrencilerin bilgi teknolojilerini kullanma becerilerini geliştirir (Wechsler \& Pitts, 2004, Tschirner \& O'Brien, 2006). Öğrenciler CBS uygulamalarını kullanma konusunda isteklidirler. Böylece CBS yazılımını kullanarak farklı bir bilgi teknolojisini kullanmayı da öğrenmiş olurlar. Öğrencilerin CBS ile bilgi teknolojilerini kullanma becerilerinin artmasının yanı sıra teknoloji araçlarına karşı tutumlarının da olumlu yönde arttığı bir gerçektir (Baker, 2002).

\section{CBS’nin Eğitim Amaçlı Kullanımının Sınırlılıkları}

Günümüzde CBS'nin eğitim alanında kullanımının önemli yararlar sağlayacağına yönelik çalışmaların yapılmasına rağmen halihazırda okulların bu teknolojiyi çok düşük seviyede benimsedikleri görülmektedir. Bu durum CBS'nin diğer bilim dallarında yaygın bir şekilde kullanılmasına karşın eğitim alanında kullanımının sınırlılıklarının sorgulanmasına neden olmuştur. 
CBS'nin öğretim ortamında kullanımını sınırlandırıcı etkenlerden birinin öğretmen faktörü olduğu yapılan çalışmalarda ortaya koyulmuştur. CBS uygulamalarının eğitim alanındaki sınırlılıkları öğretmen faktörü açısından değerlendirildiğinde öğretmenlerin CBS yazılımları hakkındaki bilgilerinin yetersizlikleri ve CBS uygulamalarını gerçekleştirmek için ayıracakları zamanın kısıtlı olması öğretmenler açısından vurgulanan iki önemli problem olarak görülmektedir.

Öğretmenlerin CBS yazılımı ile ilgili teknik ve pedagojik bilgi eksiklikleri CBS uygulamalarını sınıf ortamında gerçekleştirmedeki önemli engellerdendir (Johannson, 2003, Moore, Brady, Bursek \& Francis, 2004, Baker, 2005, Bartha, 2005). CBS'nin öğretim sürecindeki etkililiği öğretmenlerin bu teknolojiyi öğrenci seviyesine uygun bir şekilde kullanabilmeleri için gerekli teknik bilgiye sahip olmalarını gerektirir. $\mathrm{Bu}$ teknoloji ile daha önce hiç karşılaşmamış ya da mevcut bilgisi ile CBS uygulamalarında karşılaşılabilecek sorunları çözemeyecek derecede yetersiz olan bir öğretmenin bu teknolojiyi öğretim süreci içerisinde etkili bir araç olarak kullanması mümkün değildir. Bu durumun farkında olan öğretmenler CBS'nin sınıf içerisinde kullanımının sonuçlarını kestiremedikleri için CBS'nin öğretim materyali olarak yapılandırılmasına çok az güvenebilmekte ve CBS'nin öğretim ortamında kullanımına karşı olumsuz bir tutum sergileyebilmektedirler (Wallace, 2004, Walker, 2004).

Öğretmenlerin CBS uygulamalarını hazırlamak ve bu teknolojiyi ders planları ve sınıf içi etkinlikler ile bütünleştirmek üzere ayıracakları zamanın k1sitlı olması da bu teknolojinin sinif ortamında kullanımını zorlayıcı etkenlerdendir (Butterick, Olkin \& Zack, 1999, Bednarz 1999, Alibrandi \& Palmer, 2001, Kerski, 2003, Meyer, Hagevik, 2003, Johansson \& Pellikka, 2005). Öğretmenlerin CBS uygulamalarını hazırlayabilmeleri için gerekli verilere ulaşmaları, bu verileri düzenleyip veritabanına uygun hale getirmeleri ve harita katmanlarına yansıtmaları oldukça zaman alıcı bir iştir. Ayrıca bu uygulamaların pedagojik açıdan uygunluğunun sağlanması ve öğretim programına uygun hale getirilmesi yine öğretmenlerin bu teknolojiyi etkili bir öğretim aracı olarak kullanabilmeleri için zamana ihtiyaç duymalarına neden olur. Öğretmenler bu nedenle de CBS teknolojisinin ögretim ortamında kullanımına uzak durmaktadırlar.

CBS'nin öğretim ortamında kullanımını sınırlandıran bir diğer önemli faktör yazılım ile ilgili zorluklardır. Yazılımın maliyetinin yüksek olmasının (Wiegand, 2001, Johansson, 2003, Kerski, 2003) yanı sira uygun temel haritaları ve veri tabanlarını elde etmenin güçlüğü (Wiegand, 2001, Johansson \& Kaivola, 2004, Akt. Bednarz \& Shee, 2006) de yazilım kullanımı ile ilgili teknik desteği bir sınırlılık olarak ortaya çıkarmaktadır. 
Okullardaki teknolojik donanımın yetersizliği de, eğitim alanında CBS teknolojisinin kullanımının sınırlı olmasına neden olmaktadır (Kerski, 2003, Walker, 2004). Teknolojik imkânları yetersiz öğretim kurumlarının eğitim teknolojileri ile ilgili yenilikleri takip etmemesi bu teknolojiden haberdar olmamalarına neden olabilmektedir.

\section{Türkiye'nin İlk ve Ortaöğretim Kurumlarında Coğrafi Bilgi Sistemleri'nin Kullanımı}

Ülkemizde CBS devletin farklı kurumlarında yaygın bir şekilde kullanılmasına karşın öğretim kurumları tarafında sadece bazı yükseköğretim kurumlarının farklı bilim dallarında öğretim programına koyularak uygulanmaya başlanmıştır. İlköğretim kurumlarında ve Coğrafya Dersi Öğretim Programının bazı kazanımlarında etkinlik olarak kullanılması önerilmesine (MEB, 2005) rağmen ortaöğretim kurumlarında henüz CBS'nin kullanımı ile ilgili uygulamalar oldukça sınırlıdır (Demirci, 2006, Şahin \& Gençtürk, 2007). Bu durumun bazı nedenleri vardır. Bunlardan en önemlileri öğretmenlerin ve okul yöneticilerinin bu teknolojinin eğitim alanında kullanımından haberdar olmayışları, CBS'nin kullanımı ile ilgili sınırlılıklarda ifade edildiği gibi öğretim süreci içerisinde kullanılabilecek CBS uygulamalarının bulunmayışı, eğitimcilerin bu teknolojiyi kullanabilecek yeterli bilgi düzeyine sahip olmamaları ve okulların teknolojik alt yapılarının bu uygulamaları gerçekleştirecek düzeyde olmamasıdır. Bu olumsuzlukları gidermek üzere son birkaç yıldır Türkiye'de CBS'nin ilk ve ortaöğretim kurumlarında yaygınlaştırılmasını amaç edinen çalışmalar yapılmaktadır.

Demirci (2006) “Coğrafi Bilgi Sistemlerinin Türkiye'deki Yeni Coğrafya Dersi Öğretim Programına Göre Coğrafya Derslerinde Uygulanabilirliği” başlıklı çalışmasında, CBS'nin coğrafya derslerinde kullanımını sınırlayan faktörleri tespit etmek ve çözüm yollarını bulabilmek amaciyla 7 özel okuldan 14 öğretmen üzerinde bir eğitim programı düzenlemiştir. Bu program çerçevesinde öğretmenlere CBS yazılımı, CBS ile ders geliştirme ve örnek ders anlatımı konularında laboratuvar ortamında uygulamalı bir eğitim verilmiştir. Araştırmacı bu eğitim programının sonucuna göre CBS'nin ortaöğretim düzeyinde uygulanabilirliği ile ilgili birtakım sınırlılıkları farklı boyutları ile ortaya koymuştur. Bu sınırlılıkların okul boyutunda, okul yönetimlerinin CBS'nin önemini anlayamamış olmaları, okulların bilgisayar alt yapılarının yetersizliği, okullarda CBS yazılımının ve CBS uygulamalarında kullanılacak ilgili sayısal verilerin bulunmayışı yer almaktadır. Öğretmenler açısından CBS'nin uygulanabilirliği ile ilgili sinırlılıklarda öğretmenlerin CBS'nin coğrafya ögretimine katkılarını bilmemeleri, bu teknolojinin teknik ve pedagojik 
kullanımı ile ilgili bilgilerinin yetersizliği, bilgisayar kullanma düzeylerinin düşük seviyede olması ve CBS'yi kullanma konusundaki isteklerinin ve motivasyonlarının düşük olması dikkat çekmektedir. Eğitim sistemi boyutunda, öğretmenlerin CBS eğitimi ile ilgili yeterli desteği almamış olmaları, öğretmenlere CBS uygulamaları ile ilgili örnek uygulamaların yer aldığı kitap, dergi ve web sitelerinin sunulmaması, CBS'nin eğitim alanında kullanımı ile ilgili yeterli nicelik ve nitelikteki projelerin hayata geçirilmemiş olması önemli faktörlerdir. Coğrafya Dersi Öğretim Programında yer alan sınırlılıklarla ilgili tespitler, CBS'nin öğretim programı ile bütünleştirilirken zamanlama ile ilgili problemlerin yaşandığ 1 , CBS'nin sadece haritalama yönüne ağırlık verildiği, öğretim programında örnek CBS uygulamaları ve ilgili kaynakların bulunmadığı ve CBS'nin öneminin öğretmenlerin bu teknolojiyi kullanma konusunda çaba gösterecekleri kadar güçlü yansıtılmadığı şeklindedir.

Koçak (2007) ise "Yeni Coğrafya Öğretim Programında Bazı Tarım Konularının Öğretiminde Coğrafi Bilgi Sistemlerinin Kullanımı" başlıklı yüksek lisans tezinde, Coğrafya Dersi Öğretim Programında CBS'nin kullanımına yönelik önerilerde bulunulduğunu ancak CBS uygulamaları ile ilgili somut örneklerin olmadığını ifade etmiş ve ortaöğretim coğrafya dersinde yer alan tarım coğrafyası konusu ile ilgili örnek CBS uygulamaları hazırlamıştır.

Aladağ (2007), "İlköğretim 7. Sınıf Sosyal Bilgiler Dersinde Coğrafi Bilgi Sistemleri Kullanımının Öğrencilerin Akademik Başarı ve Derse Karşı Motivasyonlarına Etkisi” başlıklı doktora tezinde geliştirdiği CBS uygulamalarının ilköğretim 7. sınıf öğrencilerinin başarılarına ve derse karşı motivasyonlarına etkisini incelemiş ve CBS uygulamalarının öğrencilerin hem başarı seviyelerinde hem de derse karşı motivasyonlarında olumlu yönde etkisi olduğunu ortaya koymuştur.

Baloğlu Uğurlu (2007), “Sosyal Bilgiler Dersinde Türkiye'nin Doğal Kaynakları Konusunun Coğrafi Bilgi Sistemleri ile Öğretiminin Öğrencilerin Tutum ve Başarısına Etkisi" başlıklı doktora tezinde geliştirdiği CBS uygulamalarının ilköğretim 6. sınıf öğrencilerinin başarı düzeylerini olumlu yönde etkilediği ve öğrencilerin CBS uygulamalarına karşı yüksek düzeyde olumlu bir tutuma sahip oldukları sonucuna varmıştır.

Yapılan bu araştırmalar ilk ve ortaöğretim kurumlarında gerek teknik altyap1 gerekse CBS uygulamaları hazırlandığında bu bilgi teknolojisinin eğitim amaçlı kullanabilirliğini ortaya koymaktadır. Nitekim, Milli Eğitim Bakanlığı da bu gelişmeleri göz önünde bulundurarak CBS uygulamalarını ilk ve ortaöğretim kurumlarında yaygınlaştırmaya yönelik önemli adımlar 
atmaktadır. Milli Eğitim Bakanlığı'nın 29-31 Mart 2007 tarihinde Gebze'de TÜBİTAK ile yaptığ 1 ortak akıl toplantısında hazırlanabilecek alternatif kamu projelerinden biri olarak CBS teknolojisinin coğrafya eğitiminde proje tabanlı ve uygulamalı öğretimin planlanması için kullanımı ile ilgili bir projenin de gerçekleştirilebileceği sonucuna varılmıştır. Bu projenin öneminden söz edilirken, CBS'nin Türkiye'de kullanımının, coğrafya öğretiminin yeniden yapılandırılması ve proje merkezli, problem çözümüne dayalı, uygulama ağırlıklı ve öğrenci merkezli bir yapıya dönüştürülebilmesi için çok önemli firsatlar sunduğu vurgulanmaktadır (TUBİTAK\&MEB, 2007).

\section{TARTIŞMA ve SONUÇ}

Eğitimde bilgi teknolojilerinin kullanımı ile ilgili yeni bir uygulama olan CBS, Milli Eğitim Bakanlığı'nın eğitim sistemini ileri teknolojilerle kaynaştırmak, yeniliklerle desteklemek, ölçüp değerlendirerek sürekli geliştirmek, bilişim teknolojilerini en üst düzeyde kullanarak öğrenci merkezli ve proje tabanlı eğitimi sağlamak üzere gerçekleştirmeyi hedeflediği bilişim teknolojisi vizyonu ile birebir örtüşmektedir (MEB, 2007). CBS'nin eğitim alanında yapılan uygulamaları eğitim amaçlı CBS kullanımının öğrenme ve öğretim sürecine ne derece önemli katkılarda bulunduğunu ispatlamaktadır.

CBS uygulamaları öğretim süreci ile bütünleştirilirken bazı zorlukların yaşanacağı da bir gerçektir. Zorlukların aşılması için öncelikle bu teknolojiyi öğretim ortamında kullanacak olan öğretmenlerin CBS'ye karşı güvenlerini artırmak ve olumlu bir tutuma sahip olmalarını sağlamak gerekmektedir. Öğretmenlerin CBS ile yapılacak örnek uygulamaların sonuçlarını görmeleri onların bu teknolojiyi benimsemelerini sağlayabilir. Ayrıca öğretmenlerin CBS teknolojisine karşı olumsuz bir tutuma sahip olmaları kendilerinin teknolojik bilgi ve beceri konusundaki yetersizlikleri ile ilgili olabilmektedir. Öğretmenlerin hem bilgisayar hem de CBS teknolojisini kullanma becerilerini sağlamak için CBS uzmanları ve şirketlerinden destek alınarak düzenlenebilecek hizmet içi eğitim programları ile bu engelin önemli ölçüde aşılabileceği açıktır.

Öğretmenler sadece CBS'yi kullanma konusunda değil, CBS destekli öğretim ortamında kullanılacak ders materyallerini hazırlama konusunda da eğitilebilirler. Ancak öğretmenlerin CBS tabanlı haritaları hazırlarken verilere ulaşma ya da haritaları hazırlamaya ayıracakları zamanlarının kısıtlı olması, bu problemin öğretim materyallerinin öğretmenlerin pedagojik ve içerik bilgilerinden de destek alınarak CBS uzmanları tarafından hazırlanması ile çözümlenebilir. 
Öğretmenlerin CBS'ye karşı tutumlarının yanı sıra okulların teknolojik açıdan yeterlilikleri de CBS'yi uygulama konusundaki sıkıntıları en aza indirgemek açısından önemlidir. Milli Eğitim Bakanlığı'nın ilk ve ortaöğretim kurumlarına bilgi teknolojisi araçlarını kazandırarak, bu teknolojilerden aktif olarak yararlanılmasını sağlamak üzere yaptıkları uygulamalar geçmişten bu yana devam etmektedir. Milli Eğitim Bakanlığı'nın 08.01.2007 tarihli genelgesine göre şu anda bakanlığa bağlı okul ve kurumlarda yabancı, yerli kaynaklar ve çeşitli özel kuruluşların katkıları ile yaklaşık 29.264 bilişim teknolojisi sınıfı kurulmuştur (MEB, 2007). Bu sayının her geçen gün daha da artacağı düşünülürse CBS’yi ilk ve ortaöğretim kurumlarında yaygınlaştırmanın mümkün olduğu anlaşılabilir.

CBS'nin öğretim programı ile bütünleştirilmesinin, öğretim ortamında etkili bir araç olarak kullanılmasında önemli bir faktör olacağı da unutulmamalıdır. CBS öğretim programları ile bütünleştirilirken her eğitim teknolojisi aracının öğretim ortamına entegrasyonunda olduğu gibi pedagojik, teknolojik ve içerik bilgisinin birbiriyle etkileşim halinde olması şarttır (Mishra \& Koehler, 2006).

Sonuç olarak, CBS'yi ilk ve ortaöğretim kurumlarında yaygınlaştırmak eğitim alanında uygulamaları henüz çok yeni bir bilgi teknolojisinin kullanımı açısından önemli bir gelişme olacaktır. Uygulanan her yenilikçi düşüncede olduğu gibi CBS uygulamalarında da bazı zorlukların yaşanması mümkündür. Ancak gelişen teknolojiye ve çağdaş bir eğitim sistemine uyum sağlamak isteniyorsa, günümüzün modern bilgi teknolojilerinden olan CBS'nin temel becerilerinin ilköğretim seviyesinden itibaren öğrencilere kazandırılması için gerekli çabanın gösterilmesi zorunludur. 


\section{KAYNAKLAR}

Aladağ, E. (2007). "İlköğretim 7. Sınıf Sosyal Bilgiler Dersinde Coğrafi Bilgi Sistemleri Kullanımının Öğrencilerin Akademik Başarı ve Derse Karşı Motivasyonlarına Etkisi”, Yayımlanmamış Doktora Tezi, Gazi Üniversitesi Eğitim Bilimleri Enstitüsü, Ankara.

Alibrandi, M. \& Palmer, J. (2001). Making a Place for Technology in Teacher Education with Geographic Information Systems (GIS), Contemporary Issues in Technology and Teacher Education [Online serial], 1(4) 483-500.

Baker, T. R. (2001). The History and Application of GIS in K-12 Education. GIS@development, 5(1),29-31.

Baker, T. R. (2002). "The Effects of Geographic Information System (GIS) Technologies on Students' Attitudes, Self-Efficacy and Achievement in Middle School Science Classrooms.", PhD Dissertation, The University of Kansas, ProQuest Digital Dissertations, UMI Number: 3083167.

Baker, R. (2005) Internet-Based GIS Mapping in Support of K-12 Education, The Professional Geographer, 57 (1), 44-50.

Baloğlu Uğurlu, N. (2007). "Sosyal Bilgiler Dersinde Türkiye'nin Doğal Kaynakları Konusunun Coğrafi Bilgi Sistemleri ile Öğretiminin Öğrencilerin Tutum ve Başarısına Etkisi”, Yayımlanmamış Doktora Tezi, Gazi Üniversitesi Eğitim Bilimleri Enstitüsü, Ankara.

Bartha, G. (2005). Objectives of GIS Teaching in Higher Education: Developing Experts or Training Teachers? HERODOT Thematical Network Publications.

Bednarz, S. W. (1999). Impact and Success: Evaluating a GIS Training Institute, Nineteenth Annual ESRI International User Conference, 26-30 July, San Diego.

Bednarz S. W. \& Schee J. V. (2006). Europe and the United States: The Implementation of Geographic Information Systems in Secondary Education in Two Contexts, Technology, Pedagogy and Education, 15(2), 191-205.

Broda, H. \& Baxter, R. (2003). Using GIS and GPS Technology as an Instructional Tool, The Social Studies, 94(4), 158-160.

Çınar, O., Teyfur, E. \& Teyfur, M. (2006). İlköğretim Okulu Öğretmen ve Yöneticilerinin Yapılandırmacı Eğitim Yaklaşımı ve Programı Hakkındaki Görüşleri, Eğitim Fakültesi Dergisi, 7 (11), 47-64.

Demirci, A. (2006). Coğrafi Bilgi Sistemlerinin Türkiye'deki Yeni Coğrafya Dersi Öğretim Programına Göre Coğrafya Derslerinde Uygulanabilirliği, 4. Coğrafi Bilgi Sistemleri Bilişim Günleri Kongresi, 13-16 Eylül 2006, Fatih Üniversitesi, İstanbul. 
Drennon, C. (2005). Teaching Geographic Information Systems in a Problem Based Learning Environment, Journal of Geograhy in Hihger Education, 29(3), 385-402.

Duit, R., \& Treagust, D. F. (1998). International Handbook of Science Education, In B. J. Fraser and K. G. Tobin (Eds.), Learning in Science from Behaviourism towards Social Constructivism and Beyond, (pp. 3-25), London: Kluwer Academic Publishers.

ESRI. (1998). "GIS in K-12 Education" An ESRI White Paper [Online]. 5 Mayıs 2008, http://esri.com/pub/k12-lib/docs/k12educ2.pdf.

Hagevik, R. A. (2003). "The Effects of Online Science Instruction Using Geographic Information Systems to Foster Inquiry Learning of Teachers and Middle School Science Students", PhD Dissertation, North Caroline State University, ProQuest Digital Dissertations, UMI Number: 765022051 .

Johansson, T. (2003). GIS in Teacher Education - Facilitating GIS Applications in Secondary School Geography, "ScanGIS'2003 - Proceedings of the 9th Scandinavian Research Conference on Geographical Information Science, June 4-6, Espoo.

Johansson, T. \& Pellikka, P. (2005). Interactive Geographical Information Systems (GIS) Applications for European Upper Secondary Schools, Recent Research Developments in Learning Technologies, 2, 505-509.

Keiper, T. A. (1999). GIS for Elementary Students: An Inquiry into a New Approach to Learning Geography, Journal of Geography, 98(2), 47-59.

Kerski, J. (2003). The Implementation and Effectiveness of Geographic Information Systems Technology and Methods in Secondary Education, Journal of Geography, 102, 128-137.

Koçak, H. (2007). "Yeni Coğrafya Öğretim Programında Bazı Tarım Konularının Öğretiminde Coğrafi Bilgi Sistemlerinin Kullanımı.", Yayımlanmamış Yüksek Lisans Tezi, Afyon Kocatepe Üniversitesi Sosyal Bilimler Enstitüsü, Ankara.

Lee, J. W. (2005). "Effect of GIS Learning on Spatial Ability", PhD Dissertation, Texas A\&M University, ProQuest Digital Dissertations, UMI Number: 3218369.

M. E. B. (2005). Coğrafya Dersi Öğretim Programı, Ankara: Gazi Kitabevi.

M. E. B. Eğitim Teknolojileri Genel Müdürlüğü, (2007). Bilişsim Teknolojileri Sınıflarının Halka Açılması, B.08.0.ETG.0.21.01.04.00-000.2/211 Sayılı Genelge, 7 May1s 2008, http://egitek.meb.gov.tr/Egitek/HaberDuyuru/ BTSinilarininHalkaAc_Genelge_2007_4.pdf. 
Meyer, J.W., Butterick, J., Olkin, M., \& Zack, G. (1999).GIS in the K-12 Curriculum: A Cautionary Note, Professional Geographer, 51(4), 571578.

Mishra, P. \& Koehler, M. J. (2006). Technological Pedagogical Content Knowledge: A New Framework for Teacher Knowledge, Teachers College Record, 108 (6), 1017-1054.

Moore, S., Brady, J., Bursek J. \& Francis L. (2004). An Ocean of Issues: Designing GIS-Based Lessons for Secondary Schools, 4th Annual ESRI Education User Conference, 7-10 August, San Diego.

Şahin, S. \& Gençtürk, E. (2007). Kuram ve Uygulamada Coğrafya Eğitimi, S. Karabağ ve S. Şahin (Ed.) Coğrafya Eğitimi ve Bilgi İletiş̧im Teknolojileri (ss. 175-222). Ankara: Gazi Kitabevi.

Tschirner, S. \& O'Brien M. (2006). TEGIS -Technology in Education with GIS, Presentation at the National Conference 2006 of the Computer Education Society of Ireland CESI - 'Schools in the Digital Age'.

TUBİTAK\&MEB. (2007). Ulusal Eğitim Kamu Araştırma Programı, [Online], 9 Aralık 2007, http://www.tubitak.gov.tr/tubitak_content_files/ARDEB/kamag/Ulusal_Egi tim_Kamu_Arastirma_Programi.pdf.

Walker, S. L. (2004). GIS and Students as Scientists, Constructivist Approaches to Science Curriculum Restructuring, Geographic Learning Environments Monograph, No. 1.

Wallace, R. M. (2004) A Framework for Understanding Teaching with The Internet, American Educational Research Journal, 41(2), 447-488.

Wechsler, S. P. \& Pitts, L. A. (2004). GIS in High School Integrates Geography with Technology: A Case Study, The California Geographer, 44, 38-54.

West, B. (2003). Student Attitudes and the Impact of GIS on Thinking Skills and Motivation, Journal of Geography, 102(6), 267-274.

Wiegand, P. (2001). Forum Geographical Information Systems (GIS) in Education, International Research in Geographical and Environmental Education, 10(1), 68-71.

Xioamin, Q. (2006). "Geographic Information Technologies: An Influence on The Spatial Ability of University Students?", PhD Dissertation, Texas State University, ProQuest Digital Dissertations, UMI Number: 3221520. 